\title{
A model of human whole blood lymphokine release for in vitro and ex vivo use
}

\author{
Corinna Hermann ${ }^{1}$, Sonja von Aulock ${ }^{1}$, Kathrin Graf, Thomas Hartung* \\ Biochemical Pharmacology, University of Konstanz, 78457 Constance, Germany
}

\begin{abstract}
Endotoxin (lipopolysaccharide, LPS) inducible cytokine release by human whole blood is increasingly used to model inflammatory responses in vitro, to detect the presence of pyrogenic contaminations as well as to monitor disease states or immunomodulatory treatments ex vivo. However, the LPS-stimulated blood model primarily allows the assessment of monocyte responses. Here, a whole blood model was established which allows assessment of lymphocyte responses. Four different superantigens, namely staphylococcal enterotoxin A and B (SEA, SEB), toxic shock syndrome toxin-1 (TSST-1) or streptococcal exotoxin A (SPEA) were tested with respect to the induction of lymphokine release. All superantigens were capable of inducing significant amounts of the lymphokines interferon- $\gamma$ (IFN $\gamma$ ), interleukin 2 (IL-2), IL-4, IL-5, IL-13 and tumor necrosis factor $\beta$ $(T N F \beta)$ after $72 \mathrm{~h}$ of incubation. Concentration-dependencies and kinetics were determined. Blood from 160 healthy donors was used to assess the variability of SEB-inducible lymphokine release. Interindividual differences were more pronounced compared to LPS-inducible monokine release. However, the individual response was maintained when blood from six donors was tested once a week for 8 weeks, suggesting that the individual response represents a donor characteristic. The model appears to be suitable for the evaluation of immunomodulatory agents in vitro as well as ex vivo.
\end{abstract}

Abbreviations: G-CSF, granulocyte colony-stimulating factor; IFN, interferon; IL, interleukin; LPS, lipopolysaccharide; PBMC, Peripheral blood mononuclear cells; S.a.e., Salmonella abortus equi; SEA, staphylococcal enterotoxin A; SEB, staphylococcal enterotoxin B; SPEA, streptococcal exotoxin A; TSST, toxic shock syndrome toxin; tlr, toll-like receptor; TNF, tumor necrosis factor.

* Corresponding author. Tel.: +49-7531-884116; fax: +497531-884117.

E-mail address: Thomas.Hartung@uni-konstanz.de (T. Hartung).

${ }^{1}$ These authors have contributed equally.

\section{Introduction}

In 1982, Kirchner et al. (1982) suggested the use of human whole blood to study endotoxin-inducible IFN release. Although this first description of a human whole blood cytokine release model actually measured a lymphokine, later variants of the model predominantly determined monokine release (Desch, 1989; DeForge and Remick, 1991; Elsasser-Beile et al., 1991; Wilson et al., 1991). The main stimulus employed is Gram-negative endotoxin, which directly triggers monocyte activation. Subsequent IFN $\gamma$ formation by lymphocytes is induced via TNF $\alpha$ and IL-12 
among others (Hartung et al., 1999; Boneberg et al., 2000). However, whole blood cytokine release is also inducible by Gram-positive lipoteichoic acid (LTA) (Morath et al., 2001; Hermann et al., 2002) which signals via the toll-like receptor (tlr) 2 on the monocyte (Lehner et al., 2001), not via tlr-4 which is crucial for LPS. The fact that healthy donors react very uniformly to LPS and its Gram-positive counterpart allowed us to develop a pyrogen test based on this reaction (Hartung and Wendel, 1995, 1996) which is currently being validated (Hartung et al., 2001) in collaborative studies for inclusion into pharmacopoeias.

The model of whole blood monokine release has been employed to characterize various patient groups over the years, e.g. multiple sclerosis (Beck et al., 1988; Chofflon et al., 1991, 1992), leishmaniasis (Frankenburg and Klaus, 1991), rheumatoid arthritis (Zangerle et al., 1992), sepsis (Volk et al., 1991; Ertel et al., 1993, 1994), carcinoma (Elsasser-Beile et al., 1993a,b), HIV infection (Hartung et al., 1998) and borreliosis (Diterich et al., 2001). The involvement of the immune system in these diseases was established and standardized kit versions are now commercially available, since the method appears to have diagnostic value, especially in sepsis patients (Reinke et al., 1999). The method also proved to be valuable for ex vivo monitoring of immunomodulatory treatments, e.g. in healthy volunteers treated with granulocyte colony-stimulating factor (G-CSF) (Hartung et al., 1995, 1999; von Aulock et al., 2000) or IL-10 (Chernoff et al., 1995) or patients treated with granulocyte-macrophage colony-stimulating factor (Hartung et al., 2000). The numerous applications of the whole blood monokine release model prompted the development of a similar standardized lymphokine release model. Microbial superantigens are a family of protein exotoxins that circumvent the mechanisms of conventional MHC-restricted antigen processing and bind directly as intact proteins to the MHC class II molecule on antigen presenting cells and to the T-cell receptor (Llewelyn and Cohen, 2002). The range of microorganisms assumed to release superantigens is wide and bacteria such as staphylococci, streptococci, yersiniae, mycobacteria as well as viruses are included (Michie and Cohen, 1998). The best characterized superantigens are staphylococcal enterotoxins and streptococcal pyrogenic exotoxin that trigger the staphylococcal and the streptococcal toxic shock syndromes, respectively. The superantigens bind to the variable region of the beta chain ( $V \beta$ region) and lead to the activation of up to $25 \%$ of an individual's Tcells. Different superantigens bind to diverse characteristic V $\beta$ regions (Hudson et al., 1993) leading to T-cell activation and the subsequent release of pro-inflammatory cytokines and T-cell proliferation (Blackman and Woodland, 1995; Krakauer, 1999).

Here, the prerequisites and characteristics of a human whole blood lymphokine release model employing such exotoxins are defined extending earlier approaches by our own group and others (Brand et al., 1992, 1997; Hartung et al., 1995, 1999; Baum et al., 1999; Westerholt et al., 2000). The model appears to be useful in defining the immune characteristics of donors, states of disease and the effect of immunomodulatory and/or immunotoxic agents.

\section{Materials and methods}

\subsection{Isolation of monocytes or lymphocytes}

Peripheral blood mononuclear cells (PBMC) of healthy volunteers were prepared with $\mathrm{CPT}^{\mathrm{TM}}$ Cell Preparation Tubes (Becton Dickinson, Franklin Lakes, USA) and used for isolation of monocytes or lymphocytes by magnetic cell sorting according to the manufacturer's protocol. Monocytes were isolated with the Monocyte Isolation Kit from Miltenyi Biotec (Bergisch-Gladbach, Germany). Lymphocytes were obtained by negative selection with CD14 MicroBeads (Miltenyi Biotec).

\subsection{Whole blood cytokine responses}

Incubations of human whole blood in the presence of the bacterial stimuli were performed essentially as described (Hartung et al., 1995). Briefly, heparinized blood freshly taken from healthy volunteers was diluted five-fold with RPMI 1640 (BioWhittaker, Verviers, Belgium) containing 2.5 IU heparin (Liquemin N 25000, Hoffmann LaRoche, Grenzach-Whylen, Germany), $100 \mathrm{IU}$ penicillin/100 $\mu \mathrm{g}$ streptomycin (Biochrom, Berlin, Germany) per ml. After addition of the bacterial stimuli LPS from Salmonella abortus equi (S.a.e., Sigma, Deisenhofen, Germany), LTA (prepared as previously described by Morath et al., 2001), SEA (Sigma), SEB (Sigma), TSST-1 (Sigma), 
SPEA (a kind gift from Prof. Dr. J. Cohen, London, UK), phytohaemagglutinin (PHA, Sigma) or the antibodies anti-TNF $\alpha(10 \mu \mathrm{g} / \mathrm{ml}$, Endogen, Woburn, USA $)$ and anti-IFN $\gamma$ (in-house preparation, $1 \%$ serum raised in a rabbit immunized with human IFN $\gamma$, a gift from Thomae, Biberach, Germany), the samples were incubated in polypropylene vials (Eppendorf, Hamburg, Germany) or vacutainers (BD Biosciences, Heidelberg, Germany) in the presence of $5 \% \mathrm{CO}_{2}$ at $37{ }^{\circ} \mathrm{C}$ for the times indicated. Then, after shaking, the cells were pelleted by centrifugation $(400 \times g, 1.5 \mathrm{~min})$ and the cell-free supernatants were stored at $-70{ }^{\circ} \mathrm{C}$ for cytokine determinations.

The Limulus Amoebocyte Lysate test (BioWhittaker, detection limit $0.1 \mathrm{EU} / \mathrm{ml}$ ) was used to determine endotoxin contaminations.

\subsection{ELISA}

Cytokines were determined by a commercial ELISA procedure for high sensitivity-IL-4 (Biosource, Solingen, Germany) or in-house ELISA procedures based on antibody pairs against human $\mathrm{TNF} \alpha, \mathrm{IFN} \gamma$ (Endogen), IL-2, IL-6 (R\&D, Wiesbaden, Germany), IL-4, IL-5, IL-13, TNF $\beta$ (Pharmingen, Hamburg, Germany).

Binding of biotinylated antibody was quantified using streptavidin-peroxidase (Jackson Immuno Research, West Grove, PA, USA) and the substrate TMB (3,3'5,5'tetramethylbenzidine, Sigma). Recombinant cytokines used as standards were obtained from the National Institute for Biological Standards and Controls, London, UK (TNF $\alpha$ ), Genzyme, Ruesselsheim, Germany (IL-6), Thomae (hu IFN $\gamma$ ), Endogen (IL-2) and Pharmingen (IL-5, IL-13, TNF $\beta$ ). The low levels of IL- 4 detected by the in-house IL-4 assay were confirmed employing a commercial high-sensitivity ELISA (Biosource) showing a correlation of $r_{\text {Pearson }}=0.9, p<0.001$.

In order to exclude inter-assay variations the cytokine ELISAs depicted in Figs. 6 and 7 were performed by the same person in one run for each cytokine measured.

\subsection{Flow cytometry}

The purity of the isolated monocytes and lymphocytes was determined by staining with anti-CD 45 and
anti-CD14 labeled with PE or FITC (BD Biosciences), and gating for live, propidium iodide-negative (500 $\mathrm{ng} / \mathrm{ml}$, Sigma) cells. For the intracellular determination of $T N F \alpha$, whole blood was incubated with $100 \mathrm{ng} / \mathrm{ml}$ SEB for $14 \mathrm{~h}$ as described above. Then Brefeldin A (Sigma) was added to give a final concentration of 5 $\mu \mathrm{g} / \mathrm{ml}$ and cells were incubated for another $4 \mathrm{~h}$. Aliquots $(100 \mu 1)$ of the resuspended cells were stained with anti-CD45-PerCP and anti-CD14-FITC for 30 min at room temperature. After washing once, they were incubated with $1 \mathrm{ml} \mathrm{Cell} \mathrm{Fix/Perm} \mathrm{for} 20 \mathrm{~min}$ at 4 ${ }^{\circ} \mathrm{C}$. After two washes with Cell Perm/Wash, cells were stained with anti-TNF $\alpha$-PE for $30 \mathrm{~min}$ and measured after two more washes in a FACS Calibur (all BD Biosciences).

\subsection{Statistics}

Statistical analysis was performed using the GraphPad InStat program (GraphPad Software, San Diego, USA). All data are presented as mean \pm SEM. Student's $t$-test was used to compare paired samples. Comparison of the IL-2 or IL-4 levels was done by Pearson correlation. Cytokine levels are given per $\mathrm{ml}$ blood, i.e. corrected for the dilution factor 5 in the $20 \%$ blood incubation.

\section{Results}

LPS, a constituent of the membrane of Gramnegative bacteria and the secreted superantigen SEB were compared for their relative potencies to induce the release of monokines and lymphokines. Human whole blood was incubated in the presence of the different immune stimuli for 24,48 and $72 \mathrm{~h}$ and the release of the different monokines TNF $\alpha, \mathrm{IL}-1 \beta$ and IL-6 and of the lymphokines IFN $\gamma$, IL-2, IL-4, IL-5, IL-13 and TNF $\beta$ was measured by ELISA. As indicated in Table 1, LPS, even at a the lowest concentration of $1 \mathrm{ng} / \mathrm{ml}$, and SEB induced the release of all monokines and the lymphokine IFN $\gamma$, while only the superantigen SEB was capable of inducing the release of significant amounts of the lymphokines IL-2, IL-4, IL-5, IL-13 and TNF $\beta$. Since contamination of SEB preparations with LAL-negative Gram-positive immune stimuli such as LTA cannot be excluded, control experiments employing highly purified LTA (Morath 
Table 1

LPS- and SEB-inducible cytokine release from human whole blood incubated for different time periods

\begin{tabular}{|c|c|c|c|c|c|}
\hline & & LPS $[\mu \mathrm{g} / \mathrm{m}$ & & & SEB \\
\hline & & 0.001 & 0.1 & 10 & \\
\hline $\mathrm{TNF} \alpha$ & $24 \mathrm{~h}$ & $0.5 \pm 0.2$ & $0.8 \pm 0.4$ & $2 \pm 0.8$ & $0.6 \pm 0.1$ \\
\hline$[\mathrm{ng} / \mathrm{ml}]$ & $48 \mathrm{~h}$ & $0.1 \pm 0.04$ & $0.1 \pm 0.05$ & $0.7 \pm 0.3$ & $0.9 \pm 0.2$ \\
\hline & $72 \mathrm{~h}$ & $0.1 \pm 0.03$ & $0.1 \pm 0.06$ & $0.4 \pm 0.1$ & $0.9 \pm 0.3$ \\
\hline IL-1 $\beta$ & $24 \mathrm{~h}$ & $10 \pm 3.5$ & $10 \pm 3.6$ & $22 \pm 5$ & $0.4 \pm 0.1$ \\
\hline$[\mathrm{ng} / \mathrm{ml}]$ & $48 \mathrm{~h}$ & $7 \pm 2.7$ & $7 \pm 2.6$ & $61 \pm 27$ & $1.6 \pm 0.3$ \\
\hline & $72 \mathrm{~h}$ & $7 \pm 1$ & $16 \pm 8.5$ & $86 \pm 50$ & $2.6 \pm 0.5$ \\
\hline IL-6 & $24 \mathrm{~h}$ & $12 \pm 2.5$ & $16 \pm 3.8$ & $20 \pm 4$ & 0 \\
\hline$[\mathrm{ng} / \mathrm{ml}]$ & $48 \mathrm{~h}$ & $9 \pm 1.9$ & $11 \pm 3$ & $21 \pm 5$ & $0.2 \pm 0.1$ \\
\hline & $72 \mathrm{~h}$ & $21 \pm 3.5$ & $21 \pm 2.6$ & $20 \pm 2$ & $0.7 \pm 0.3$ \\
\hline IFN $\gamma$ & $24 \mathrm{~h}$ & $2 \pm 0.9$ & $3 \pm 1.3$ & $7 \pm 3.5$ & $15 \pm 4$ \\
\hline$[\mathrm{ng} / \mathrm{ml}]$ & $48 \mathrm{~h}$ & $1 \pm 0.6$ & $2 \pm 1$ & $8 \pm 3.8$ & $50 \pm 10$ \\
\hline & $72 \mathrm{~h}$ & $3 \pm 0.3$ & $6 \pm 0.8$ & $12 \pm 2$ & $62 \pm 9$ \\
\hline IL-2 & $24 \mathrm{~h}$ & 0 & 0 & 0 & $8 \pm 2.4$ \\
\hline$[\mathrm{ng} / \mathrm{ml}]$ & $48 \mathrm{~h}$ & 0 & 0 & 0 & $16 \pm 5$ \\
\hline & $72 \mathrm{~h}$ & 0 & 0 & 0 & $6 \pm 2$ \\
\hline II-4 & $24 \mathrm{~h}$ & 0 & 0 & 0 & $19 \pm 5$ \\
\hline$[\mathrm{pg} / \mathrm{ml}]$ & $48 \mathrm{~h}$ & 0 & 0 & 0 & $17 \pm 4$ \\
\hline & $72 \mathrm{~h}$ & 0 & 0 & 0 & $22 \pm 5$ \\
\hline IL-5 & $24 \mathrm{~h}$ & 0 & 0 & 0 & $0.3 \pm 0.2$ \\
\hline$[\mathrm{ng} / \mathrm{ml}]$ & $48 \mathrm{~h}$ & 0 & 0 & 0 & 0.1 \\
\hline & $72 \mathrm{~h}$ & 0 & 0 & 0 & $0.4 \pm 0.2$ \\
\hline IL-13 & $24 \mathrm{~h}$ & 0 & 0 & 0 & $0.1 \pm 0$ \\
\hline$[\mathrm{ng} / \mathrm{ml}]$ & $48 \mathrm{~h}$ & 0 & 0 & 0 & $0.4 \pm 0.1$ \\
\hline & $72 \mathrm{~h}$ & 0 & 0 & 0 & $1 \pm 0.2$ \\
\hline TNF $\beta$ & $24 \mathrm{~h}$ & 0 & 0 & 0 & $0 \pm 0$ \\
\hline$[\mathrm{ng} / \mathrm{ml}]$ & $48 \mathrm{~h}$ & 0 & 0 & 0 & $0.6 \pm 0.06$ \\
\hline & $72 \mathrm{~h}$ & 0 & 0 & 0 & $1 \pm 0.1$ \\
\hline
\end{tabular}

One milliliter $20 \%$ human whole blood was incubated in the presence of LPS from S.a.e. $(1 \mathrm{ng} / \mathrm{ml}, 100 \mathrm{ng} / \mathrm{ml}$ or $10 \mu \mathrm{g} / \mathrm{ml})$ or 100 $\mathrm{ng} / \mathrm{ml}$ SEB for 24,48 or $72 \mathrm{~h}$. The release of TNF $\alpha$, IL-1 $\beta$, IL-6, IFN $\gamma, \mathbb{L}-2, \mathbb{L}-4, \mathbb{L}-5, \mathbb{L}-13$ and TNF $\beta$ was determined in the cellfree supernatants for each time point by ELISA. The cytokine level of the unstimulated controls was below $5,3.5,2,5,7,8,8,3.5$ and 8

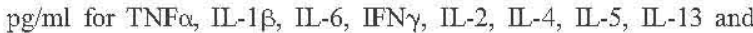
TNF $\beta$, respectively. Data are means \pm SEM of four blood donors.

et al., 2001) were carried out: $10 \mu \mathrm{g} / \mathrm{ml}$ of LTA failed to induce any lymphokine release including IFN $\gamma$ in contrast to LPS (Hermann et al., 2002) although monokine release was induced (data not shown). Notably, during the first $24 \mathrm{~h}$, the level of the SEB-induced monokines was lower, and delayed compared to LPS (Fig. 1).

In order to investigate whether SEB-stimulated $\mathrm{TNF} \alpha$ is released by lymphocytes or by monocytes, intracellular $\mathrm{TNF} \alpha$ formation was analyzed by flow cytometry. As shown in Fig. 2, the monocytes were the only leukocyte population showing SEB-inducible

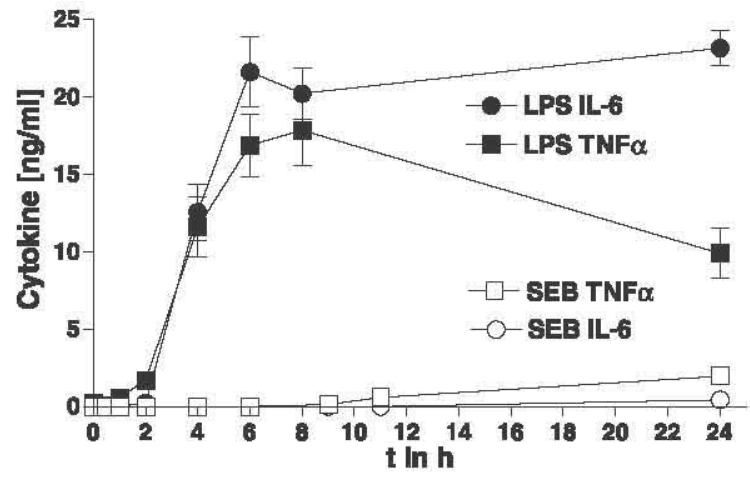

Fig. 1. Kinetics of LPS- and SEB-induced monokine release $1 \mathrm{ml}$ $20 \%$ human whole blood was incubated in the presence of $10 \mu \mathrm{g} / \mathrm{ml}$ LPS from Salmonella abortus equi or $100 \mathrm{ng} / \mathrm{ml} \mathrm{SEB}$. TNF $\alpha$ and $\mathrm{L}$ 6 were determined in the cell-free supernatants by ELISA at the time points indicated. Data are means \pm SEM of four blood donors.

$\mathrm{TNF} \alpha$ production. Isolation of monocytes with magnetic beads completely abrogated their responsiveness towards $100 \mathrm{ng} / \mathrm{ml} \mathrm{SEB}$, while the same cells still responded to $10 \mathrm{ng} / \mathrm{ml}$ LPS (TNF $\alpha: 9 \pm 0.8 \mathrm{ng}$ / $5 \times 10^{4}$ cells). This indicates that SEB-induced monocyte activation might be mediated by lymphokines. This hypothesis is further supported by the finding that in whole blood the SEB-induced TNF $\alpha$ release was inhibited in the presence of a neutralizing anti-IFNy antibody (SEB: $1.3 \pm 0.2 \mathrm{ng} / \mathrm{ml}$ vs SEB + anti-IFN $\gamma$ : $0.18 \pm 0.02 \mathrm{ng} / \mathrm{ml}, n=4, p<0.05$ ). The neutralizing capacity of the antiserum in comparison to pre-immune

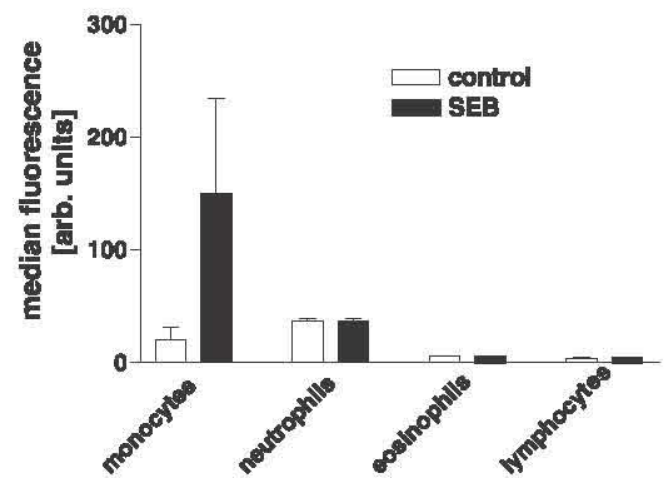

Fig. 2. SEB-induced TNF $\alpha$ is released by monocytes $1 \mathrm{ml} 20 \%$ human whole blood was incubated with $100 \mathrm{ng} / \mathrm{ml}$ SEB for $14 \mathrm{~h}$. Then $5 \mu \mathrm{g} / \mathrm{ml}$ Brefeldin A was added for a further $4 \mathrm{~h}$. Intracellular TNF $\alpha$ was measured by flow cytometry. Leukocyte populations were gated with anti-CD45-PerCP/anti-CD14-FITC. Data are median fluorescence \pm SEM of four blood donors. 
serum was confirmed by an IFN $\gamma$ ELISA, showing a neutralizing capacity of $3 \mu \mathrm{g}$ IFN $\gamma / \mathrm{ml}$ serum.

The kinetics of the release of the different lymphokines (Table 1) differed. While SEB-induced IFN $\gamma$, IL2 , IL-4 and IL-5 release could already be measured after $24 \mathrm{~h}, \mathrm{IL}-13$ and TNF $\beta$ were only detectable after $48-72 \mathrm{~h}$ of incubation. LPS-inducible IFN $\gamma$ has been shown to depend on the release of early monokines such as TNF $\alpha$ and IL-12 (Boneberg et al., 2000). However, in our case, SEB-induced IFN $\gamma$ could not be inhibited by a neutralizing anti-TNF $\alpha$ antibody (SEB: $8 \pm 1 \mathrm{ng} / \mathrm{ml}$ vs. SEB + anti-TNF $\alpha: 7 \pm 1 \mathrm{ng} / \mathrm{ml}, n=4)$. Control experiments confirmed that the anti-TNF $\alpha$ antibody was able to neutralize the biological activity of 5 ng $\mathrm{TNF} \alpha / \mathrm{ml}$ (data not shown).
Lymphocytes, isolated from PBMC by magnetic beads (purity: 99\%), still released IFN $\gamma$ upon stimulation with $100 \mathrm{ng} / \mathrm{ml} \mathrm{SEB}\left(45 \pm 4.5 \mathrm{ng} / 5 \times 10^{5}\right.$ cells, $n=4)$, indicating that the IFN $\gamma$-release was due to direct activation of lymphocytes by the superantigen.

Since the average achievable amount of all SEBinduced cytokines was maximal after $72 \mathrm{~h}$ of incubation, we next focused on this time-point and compared the SEB-inducible monokine- and lymphokine-pattern to that induced by a second staphylococcal enterotoxin, SEA. Surprisingly, incubation of human whole blood with the same concentrations of the different superantigens led to a qualitatively and quantitatively similar induction of monokines (Fig. 3a) and lymphokines (Fig. 3b). Next, we questioned whether the in-

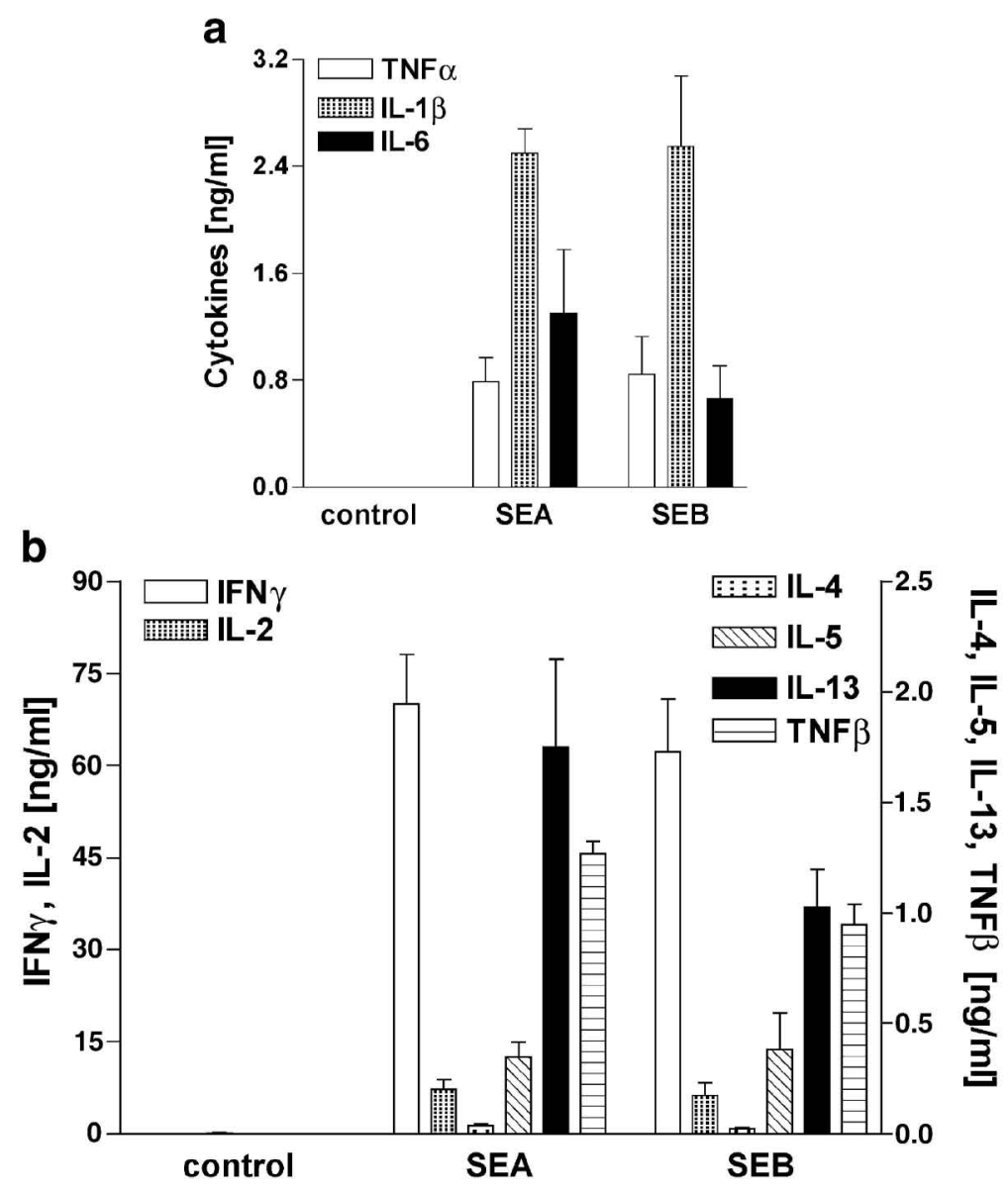

Fig. 3. SEA- and SEB-induced monokine and lymphokine release $1 \mathrm{ml} \mathrm{20 \%} \mathrm{human} \mathrm{whole} \mathrm{blood} \mathrm{was} \mathrm{incubated} \mathrm{in} \mathrm{the} \mathrm{presence} \mathrm{of} 100 \mathrm{ng} / \mathrm{ml} \mathrm{SEA}$ or SEB for $72 \mathrm{~h}$. The release of TNF $\alpha$, IL-1 $\beta$, IL-6, IFN $\gamma$, IL-2, IL-4, IL-5, IL-13 and TNF $\beta$ was determined in the cell-free supernatants by ELISA. Data are means \pm SEM of four blood donors. 
duction of lymphokine release is a property that translates to the whole class of superantigens and further investigated the superantigens TSST-1 and SPEA. Like SEB and SEA, $100 \mathrm{ng} / \mathrm{ml}$ of TSST- 1 or SPEA were able to induce the release of various lymphokines from human whole blood, with TSST-1 being more potent than SPEA (Fig. 4a and b).

SEB was chosen for all further experiments, since it is commercially available in high quality and widely used as a superantigen. Concentration-response curves from $100 \mathrm{pg} / \mathrm{ml}$ up to $1 \mu \mathrm{g} / \mathrm{ml}$ were assessed and the release of IL-2, IFN $\gamma$, IL-5, IL-13 and TNF $\beta$ was determined. Even small concentrations such as $100 \mathrm{pg} / \mathrm{ml} \mathrm{SEB}$ were able to induce the release of significant amounts of all measured lymphokines (Fig. $5 \mathrm{a}$ and $\mathrm{b}$ ), while the maxima were not exceeded with 1 $\mu \mathrm{g}$ SEB per ml.

In order to investigate the interindividual differences in the response to superantigens, the blood of 160
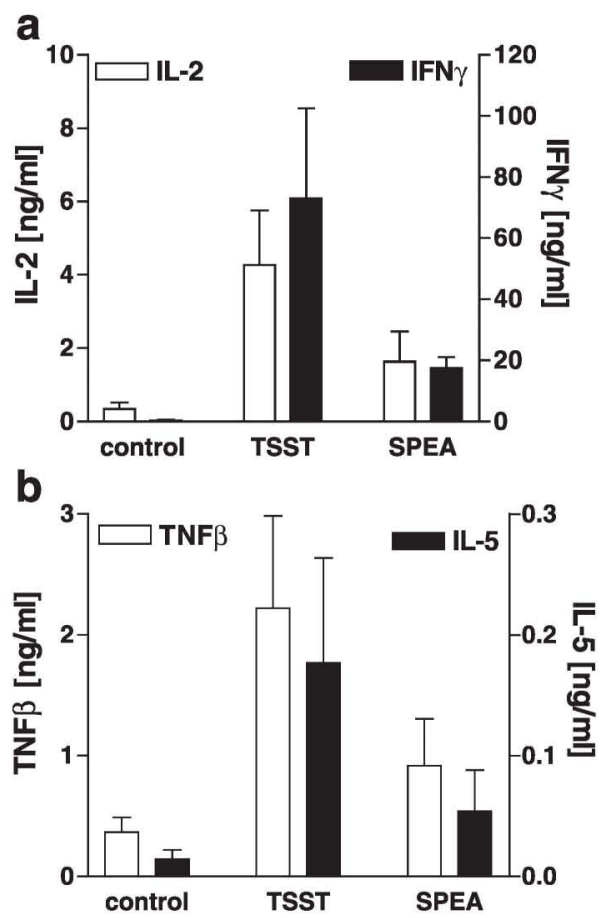

Fig. 4. TSST-1- and SPEA-induced lymphokine release $1 \mathrm{ml} 20 \%$ human whole blood was incubated in the presence $100 \mathrm{ng} / \mathrm{ml}$ TSST or $100 \mathrm{ng} / \mathrm{ml}$ SPEA for $72 \mathrm{~h}$. IL-2, IFN $\gamma$, TNF $\beta$ and IL-5 were determined in the cell-free supernatants by ELISA at the time points indicated. Data are means \pm SEM of three blood donors.
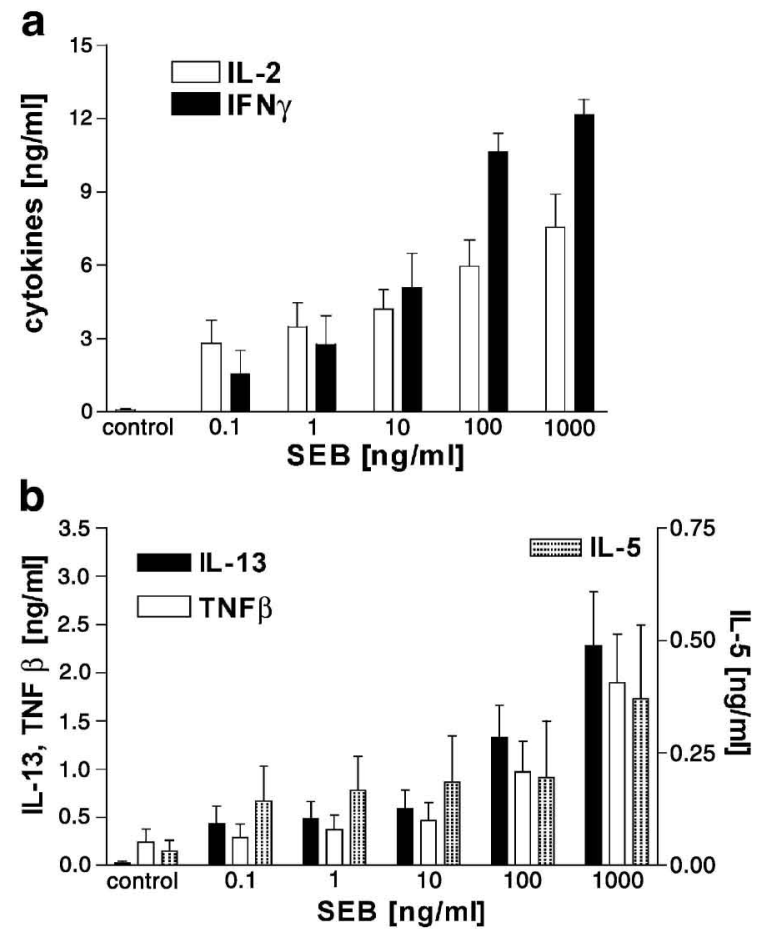

Fig. 5. Concentration-dependencies of SEB-induced lymphokine release $1 \mathrm{ml} 20 \%$ human whole blood was incubated in the presence of SEB for $72 \mathrm{~h}$ using the concentrations indicated. IL-2, IL-5, IL-13, IFN $\gamma$ and TNF $\beta$ were determined in the cell-free supernatants using ELISA procedures. Data are means \pm SEM of eight blood donors.

healthy donors was incubated in the presence of 100 $\mathrm{ng} / \mathrm{ml} \mathrm{SEB}$ or $1 \mu \mathrm{g} / \mathrm{ml}$ LPS. Fig. $6 \mathrm{a}$ and $\mathrm{b}$ show the release of the SEB-induced lymphokines IL-2 and IFN $\gamma$ in comparison to the LPS-induced release of the monokines TNF $\alpha$ and IL-1 $\beta$. The coefficient of variation $(\mathrm{cv})$ for the monokine release $(\mathrm{cvTNF} \alpha$ : $50 \%$, cvIL- $1 \beta: 44 \%$ ) is smaller than the cv for the lymphokine release (cvIL-2:77\%, cvIFNy:119\%), indicating that the extent of the interindividual differences in the stimulation with the superantigen SEB are greater than with the bacterial membrane component LPS.

To determine the variation of the individual responses over time, the blood of 10 healthy donors was stimulated with SEB twice, 4 weeks apart. The IL-2 release from a given individual was very similar at both time-points $\left(r_{\text {Pearson }}=0.79, p<0.001\right)$, suggesting a stable donor characteristic. In order to test this hypothesis, we monitored the SEB-inducible IL-4 release over 
8 weeks. As shown in Fig. 7, the amount of IL-4 released by SEB stimulation was stable for each of the six donors.

Since contamination of immune stimuli with LPS represents a major problem, we investigated the influence of LPS on SEB-stimulated lymphokine release. Some $10 \mu \mathrm{g} / \mathrm{ml}$ LPS was added together with $100 \mathrm{ng} /$ $\mathrm{ml} \mathrm{SEB} \mathrm{(LPS-free} \mathrm{as} \mathrm{indicated} \mathrm{by} \mathrm{a} \mathrm{negative} \mathrm{Limulus}$ test) to whole blood and IL-2, TNF $\beta$ and IFN $\gamma$ release were determined. LPS inhibited the SEB-inducible IL2 (SEB: $2 \pm 0.5 \mathrm{ng} / \mathrm{ml}$ vs. SEB + LPS: $0.5 \pm 0.3 \mathrm{ng}$ / $\mathrm{ml} ; p<0.05$ ) and TNF $\beta$ (SEB: $1 \pm 0.04 \mathrm{ng} / \mathrm{ml}$ vs. SEB + LPS: $0.4 \pm 0.2 \mathrm{ng} / \mathrm{ml} ; p<0.05$ ) release, while IFN $\gamma$ remained unaffected. These results demonstrate that the purity of the superantigen preparation is cru-

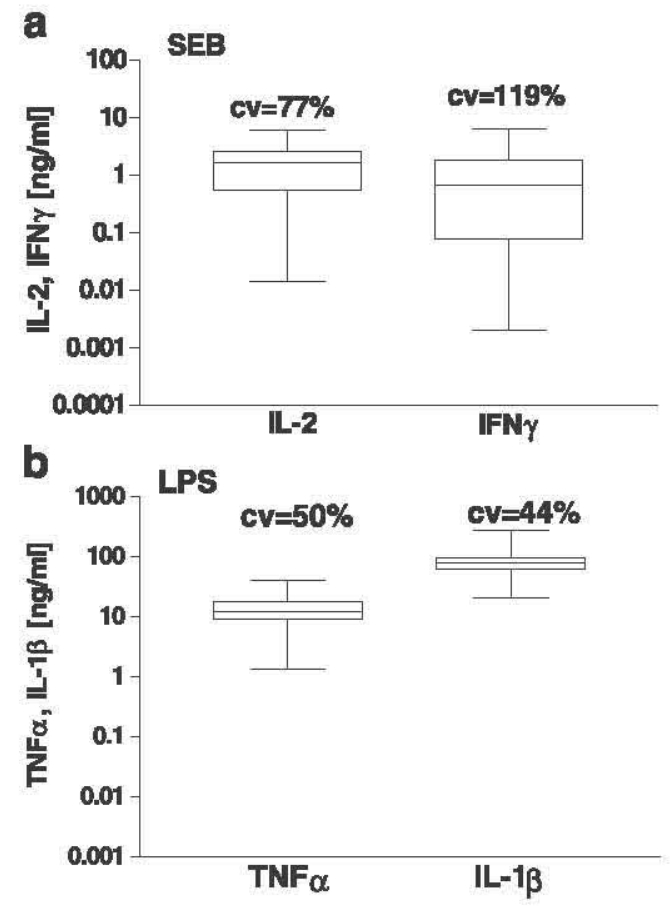

Fig. 6. Interindividual differences in response to stimulation with SEB or LPS $2 \mathrm{ml} 20 \%$ human whole blood was incubated in the presence of $100 \mathrm{ng} / \mathrm{ml} \mathrm{SEB}$ or $1 \mu \mathrm{g} / \mathrm{ml}$ LPS for 72 or $24 \mathrm{~h}$, respectively. $\mathbb{L}-2, \mathrm{IFN} \gamma, \mathrm{TNF} \alpha$ and IL-1 $\beta$ were determined in the cell-free supernatants by ELISA. The mean cytokine levels of the unstimulated controls were $23 \pm 7,58 \pm 20,136 \pm 46$ and $28 \pm 12$ $\mathrm{pg} / \mathrm{ml}$ for $\mathbb{L}-2, \mathbb{I F N} \gamma, \mathrm{TNF} \alpha$ and $\mathbb{L}-1 \beta$, respectively, while the median was zero for all cytokines. Data are median \pm quartiles and range of 160 blood donors.

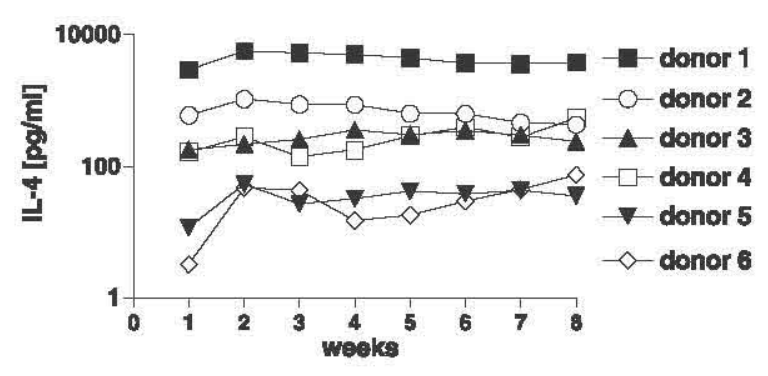

Fig. 7. Variation of the individual response to SEB stimulation over

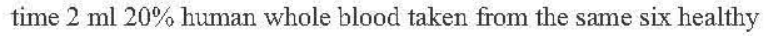
donors weekly for 8 weeks and was incubated in the presence of 100 $\mathrm{ng} / \mathrm{ml}$ SEB for $72 \mathrm{~h}$. IL-4 was determined in the cell-free supernatants by ELISA. The mean $\mathbb{L}-4$ levels of the unstimulated controls for the eight time points measured were $1464 \pm 86,9 \pm 1.5$ and $221 \pm 9 \mathrm{pg} / \mathrm{ml}$ for subject 1,2 and 5 , respectively, and less than $3.9 \mathrm{pg} / \mathrm{ml}$ for subjects 3,4 and 6 .

cial since the presence of LPS might lead to a modified lymphokine release.

\section{Discussion}

Using the four different superantigens, SEA, SEB, SPEA and TSST-1, a human whole blood model was established and characterized with respect to the assessment of lymphocyte responses. All superantigens were capable of inducing lymphokine release as shown for IFN $\gamma$, IL-2, IL-4, IL-5, IL-13 and TNF $\beta$. SEB was chosen for key experiments, because it is commercially available in high quality preparations. Several studies have used SEB for the characterization of immune status, e.g. patients infected with HIV, patients with enterohemorrhagic Escherichia coli or after exercise (Hartung et al., 1995; Baum et al., 1999; Westerholt et al., 2000). While the release of the lymphokines IFN $\gamma$, IL-2, IL-4 and IL-5 induced by SEB was already detectable at $24 \mathrm{~h}, \mathrm{IL}-13$ and TNF $\beta$ took at least $48-72 \mathrm{~h}$. Interestingly, Limulus-negative SEB, i.e. free of LPS contamination, induced only low concentrations of the monokines TNF $\alpha, \mathrm{IL}-1 \beta$ and IL6. For comparison, whole blood was incubated in parallel with $10 \mu \mathrm{g} / \mathrm{ml}$ of PHA, which induced significant amounts of IL-4 $(30 \mathrm{pg} / \mathrm{ml})$ and IFN $\gamma(20 \mathrm{ng} /$ $\mathrm{ml}$ ) but failed to induce the lymphokines IL-2 and IL-5 in our hands, even after $72 \mathrm{~h}$ of incubation. However, Hussain et al. (2002) reported significant IL-5 release from $1 / 11$ diluted whole blood which was incubated 
for 5 days. These discrepant observations may be due to methodological differences. PHA induced the monokines $\mathrm{TNF} \alpha$, IL-1 $\beta$, and IL- 6 to a similar degree as SEB. For example after $24 \mathrm{~h}$ of incubation PHA induced $0.62 \pm 0.14 \mathrm{ng} / \mathrm{ml} \mathrm{TNF} \alpha$ (SEB: $0.57 \pm 0.12$ $\mathrm{ng} / \mathrm{ml} \mathrm{TNF} \alpha$ ). This is in line with previous publications which show a low release of monokines such as IL- 6 and IL-1 $\beta$ for stimulation of whole blood with SEB or PHA even after 6-8 days of incubation (Brand et al., 1992, 1997). However, in those studies, additional SEB-induced lymphokines were not addressed. The relatively low production of $\mathrm{TNF} \alpha$ with delayed kinetics compared to LPS-inducible TNF $\alpha$ might be attributed either to lymphocytic formation of this mediator or an indirect activation of monocytes by lymphokines. Intracellular TNF $\alpha$ staining by flow cytometry suggested that monocytes are the primary source of TNF $\alpha$ in response to SEB, arguing for the latter hypothesis. This is further supported by the finding that isolated monocytes were not able to respond to SEB stimulation and that anti-IFN $\gamma$ blunted SEB-inducible $\mathrm{TNF} \alpha$ formation. In contrast, IFN $\gamma$, which is only induced indirectly by LPS via monocytic $\mathrm{TNF} \alpha$ and IL-12 release (Boneberg et al., 2000), was directly stimulated by SEB in isolated lymphocytes and, in line with this observation, anti-TNF $\alpha$-antibodies did not affect SEB-inducible IFN $\gamma$ formation in human whole blood.

Since the levels of all lymphokines were maximal at $72 \mathrm{~h}$, this condition was chosen for further studies. The different kinetics of individual endpoints might be due to sequential formation, feedback loops between lymphokines, different signal transduction cascades leading to protein expression and processing, different elimination of secreted factors or simply the different amounts of lymphokines determined in ELISA procedures with differing sensitivities. The complex cellular cross-talk of the different lymphocyte populations present in whole blood as well as monocytes and granulocytes will be difficult to analyze. However, the relatively stable response of individuals over time and a large group of volunteers, argues against a major impact of complex interactions.

The relatively narrow distribution of cytokine release levels induced (about one log-order) in a large number of healthy individuals $(n=160)$ suggests that reference values might be established for this type of reaction performed under standardized conditions.
However, this would require a reference superantigen preparation as well as the use of calibrated ELISAs. To date, this can be done on an intra-laboratory level only. If the test proves to be of diagnostic value or to be suitable for monitoring the status of the immune system in patients as well as the effects of immunomodulatory treatments, this would call for an international reference preparation of a superantigen such as SEB. An important prerequisite for the use of the model to characterize individuals over time is the relative stability of responses in a given healthy donor in the longterm. Indeed, individual responses appear to be a characteristic of the donor and only changed slightly over two months. The individual response might reflect HLA-DR genotype since this is known to correlate with cytokine production.

Whilst there have been a number of studies describing the stimulation of lymphocyte preparations, only a few have used human whole blood (summarized below), i.e. avoiding preparation artefacts. Three stimuli have been used, namely the lectin PHA, anti-CD3-antibodies and superantigens. In control experiments carried out in parallel in our study, PHA induced only a subset of lymphokines and clinical grade anti-CD3 (OKT-3, Orthoclone) did not induce any lymphokines at concentrations up to $2.5 \mu \mathrm{g} / \mathrm{ml}$ except when the blood was depleted of serum by washing (data not shown). This problem can apparently be overcome by co-stimulation with anti-CD28 (Swaak et al., 1997; Lauw et al., 2000).

The different types of whole blood lymphokine release assays have been shown to be of value for the evaluation of immune function in a broad range of patient groups, including cancer (Szopinski et al., 1999), rheumatoid arthritis (Swaak et al., 1997), tuberculosis (van Crevel et al., 1999; Hussain et al., 2002), HIV (Hartung et al., 1998; Vingerhoets et al., 1998) and ankylosing spondylitis (Brand et al., 1997). However, since very different stimuli and experimental conditions were chosen, these studies are difficult to compare. Our study therefore sought to optimize and, if possible, standardize a whole blood lymphokine release test. We have shown previously that this model is useful in identifying impairments of immune function (Hartung et al., 1998): The well-known impairment of IL-2 formation in HIV-infected patients was demonstrated ex vivo and the effect of cytokine treatment could be modeled in vitro. Furthermore, a T-helper 1/T- 
helper 2 shift was monitored by others after intravenous injection of LPS (Lauw et al., 2000). Patients with hemorrhagic uraemic syndrome due to enterohemorrhagic $E$. coli also showed a disbalanced response to SEB ex vivo (Westerholt et al., 2000). Current studies are aimed at evaluating the model for other patient groups, e.g. correlating the lymphokine response with the incidence of allergies. Similarly, the model has been employed to monitor the effect of GM-CSF treatment over 3 weeks in patients with basalioma (Hartung et al., 2000 ). It is of note that pre-filled glass vials containing cell culture medium plus/minus SEB could be used in order to standardize incubations (Hartung et al., 1998). When stored at $4{ }^{\circ} \mathrm{C}$, the pre-filled vials were stable for more than 2 years and still induced similar levels of cytokines (data not shown). This convenient set-up allows the use of this type of immune monitoring in long-term treatment studies or for large cohorts of patients.

The present model is currently being evaluated as a simple in vitro test for the immunotoxic effects of drugs and chemicals (Langezaal et al., 2001, in press). Although only a few aspects of the immune response are modeled, the approach described has several positive features. These include the simplicity and sensitivity of the response and the fact that it is based on human primary cells which are easily available and need not undergo complicated isolation procedures. It might also be helpful to develop similar models for animal blood, because this would permit ex vivo monitoring of the effect of treatment, vaccination or intoxication. Similar approaches have already been used for LPS-inducible cytokine release (Langezaal et al., 2001).

Taken together, the new standardized human whole blood model assessing SEB-inducible lymphokine release offers a simple in vitro and ex vivo measure of a crucial parameter of the immune system. The broad applicability, similar to LPS-inducible whole blood monokine release, will permit a broad range of studies.

\section{Acknowledgements}

The authors are grateful for the excellent technical assistance of I. Seuffert and the help of K. Gollmer. This study was supported by the Deutsche Forschungsgemeinschaft (Grant HA 2567/3-1).

\section{References}

Baum, M., Klopping-Menke, K., Muller-Steinhardt, M., Liesen, H., Kirchner, H., 1999. Increased concentrations of interleukin 1beta in whole blood cultures supernatants after 12 weeks of moderate endurance exercise. Eur. J. Appl. Physiol. Occup. Physiol. 79, 500-503.

Beck, J., Rondot, P., Catinot, L., Falcoff, E., Kirchner, H., Wietzerbin, J., 1988. Increased production of interferon gamma and tumor necrosis factor precedes clinical manifestation in multiple sclerosis: do cytokines trigger off exacerbations? Acta Neurol. Scand. 78, 318-323.

Blackman, M.A., Woodland, D.L., 1995. In vivo effects of superantiges. Life Sci. 57, 1717-1735.

Boneberg, E.M., Hareng, L., Gantner, F., Wendel, A., Hartung, T., 2000. Human monocytes express functional receptors for granulocyte colony-stimulating factor that mediate suppression of monokines and interferon-gamma. Blood 95, 270-276.

Brand, J.M., Kirchner, H., Neustock, P., Kruse, A., 1992. Induction of cytokines in human whole blood cultures by a mitogen derived from Mycoplasma arthritidis and by staphylococcal enterotoxin B. Immunobiology 186, 246-253.

Brand, J.M., Neustock, P., Kruse, A., Alvarez-Ossorio, L., Schnabel, A., Kirchner, H., 1997. Stimulation of whole blood cultures in patients with ankylosing spondylitis by a mitogen derived from Mycoplasma arthritidis (MAS) and other mitogens. Rheumatol. Int. 16, 207-211.

Chernoff, A.E., Granowitz, E.V., Shapiro, L., Vannier, E., Lonnemann, G., Angel, J.B., Kennedy, J.S., Rabson, A.R., Wolff, S.M., Dinarello, C.A., 1995. A randomized, controlled trial of $\mathbb{L}-10$ in humans. Inhibition of inflammatory cytokine production and immune responses. J. Immunol. 154, 5492-5499.

Chofflon, M., Juillard, C., Gauthier, G., Grau, G.E., 1991. Correlation between in vitro cytokine production and clinical evolution of multiple sclerosis patients. Schweiz. Arch. Neurol. Psychiatr. $142,107-112$.

Chofflon, M., Juillard, C., Gauthier, G., Grau, G.E., 1992. Predictive value of TNF-alpha production in patients with multiple sclerosis. Eur. Cytokine Netw. 3, 523-531.

DeForge, L.E., Remick, D.G., 1991. Kinetics of TNF, IL-6, and $\amalg$ 8 gene expression in LPS-stimulated human whole blood. Biochem. Biophys. Res. Commun. 174, 18-24.

Desch, C.E., 1989. Production of human tumor necrosis factor from whole blood ex vivo. Lymphokine Res. 8, 141-146.

Diterich, I., Harter, L., Hassler, D., Wendel, A., Hartung, T., 2001. Modulation of cytokine release in ex vivo-stimulated blood from borreliosis patients. Infect. Immun. 69, 687-694.

Elsasser-Beile, U., von Kleist, S., Gallati, H., 1991. Evaluation of a test system for measuring cytokine production in human whole blood cell cultures. J. Immunol. Methods 139, 191-195.

Elsasser-Beile, U., von Kleist, S., Fischer, R., Martin, M., Wetterauer, U., Gallati, H., Monting, J.S., 1993a. Impaired cytokine production in whole blood cell cultures of patients with urological carcinomas. J. Cancer. Res. Clin. Oncol. 119, $430-433$.

Elsasser-Beile, U., von Kleist, S., Sauther, W., Gallati, H., Monting, J.S., 1993b. Impaired cytokine production in whole blood cell 
cultures of patients with gynaecological carcinomas in different clinical stages. Br. J. Cancer 68, 32-36.

Ertel, W., Krombach, F., Kremer, J.P., Jarrar, D., Thiele, V., Eymann, J., Muenzing, S., Faist, E., Messmer, K., Schildberg, F.W., 1993. Mechanisms of cytokine cascade activation in patients with sepsis: normal cytokine transcription despite reduced CD14 receptor expression. Surgery 114, 243-250 (discussion 250-1).

Ertel, W., Jarrar, D., Jochum, M., Thiele, V., Kenney, J., Faist, E., Schildberg, F.W., 1994. Enhanced release of elastase is not concomitant with increased secretion of granulocyte-activating cytokines in whole blood from patients with sepsis. Arch. Surg. 129, 90-97 (discussion 97-8).

Frankenburg, S., Klaus, S., 1991. Production of interferon gamma in cultures of whole blood obtained in the course of and after healing of cutaneous leishmaniasis. Ann. Trop. Med. Parasitol. 85, 401-405.

Hartung, T., Wendel, A., 1995. Die Erfassung von Pyrogenen in einem humanen Vollblutmodell. ALTEX 12, 70-75.

Hartung, T., Wendel, A., 1996. Detection of pyrogens using human whole blood. In Vitro Toxicol. 9, 353-359.

Hartung, T., Doecke, W.D., Gantner, F., Krieger, G., Sauer, A., Stevens, P., Volk, H.D., Wendel, A., 1995. Effect of granulocyte colony-stimulating factor treatment on ex vivo blood cytokine response in human volunteers. Blood 85, 2482-2489.

Hartung, T., Pitrak, D.L., Stevens, P., Foote, M., Shatzen, E., Verral, S., Wendel, A., 1998. Filgrastim (r-metHuG-CSF) restores IL-2 production of blood from advanced HIV patients. J. Infect. Dis. $178,686-692$.

Hartung, T., Doecke, W.D., Bundschuh, D., Foote, M.A., Gantner, F., Hermann, C., Lenz, A., Milwee, S., Rich, B., Simon, B., Volk, H.D., von Aulock, S., Wendel, A., 1999. Effect of filgrastim treatment on inflammatory cytokines and lymphocyte functions. Clin. Pharmacol. Ther. 66, 415-424.

Hartung, T., von Aulock, S., Wendel, A., 2000. Growth factors-GCSF, GM-CSF-clinical options. In: Baue, A., Fry, D., Faist, E. (Eds.), SIRS, MODS and MOF-Systemic Inflammatory Response Syndrome, Multiple Organ Dysfunction Syndrome and Multiple Organ Failure-Pathophysiology, Prevention and Therapy. Springer Verlag, Berlin, pp. 621-629.

Hartung, T., Aaberge, I., Berthold, S., Carlin, G., Charton, E., Coecke, S., Fennrich, S., Fischer, M., Gommer, M., Halder, M., Haslov, K., Jahnke, M., Montag-Lessing, T., Poole, S., Schechtman, L., Wendel, A., Werner-Felmayer, G., 2001. Novel pyrogen tests based on the human fever reaction. The report and recommendations of ECVAM Workshop 43. European Centre for the validation of alternative methods. Altern. Lab. Anim. 29, $99-123$.

Hermann, C., Spreitzer, I., Schröder, N.M.J., Morath, S., Lehner, M.D., Fischer, W., Schütt, C., Schumann, R., Hartung, T., 2002. Cytokine induction by purified lipoteichoic acids from various bacterial species-role of LBP, SCD14, CD14 and failure to induce interleukin-12 and subsequent IFNg release. Eur. J. Immunol. 32, 541-551.

Hudson, K.R., Robinson, H., Fraser, J.D., 1993. Two adjacent residues in staphylococcal enterotoxins $\mathrm{A}$ and $\mathrm{E}$ determine $\mathrm{T}$ cell receptor V beta specificity. J. Exp. Med. 177, 175-184.

Hussain, R., Kaleem, A., Shahid, F., Dojki, M., Jamil, B., Meh- mood, H., Dawood, G., Dockrell, H.M., 2002. Cytokine profiles using whole-blood assays can discriminate between tuberculosis patients and healthy endemic controls in a BCG-vaccinated population. J. Immunol. Methods 264, 95-108.

Kirchner, H., Kleinicke, C., Digel, W., 1982. A whole-blood technique for testing production of human interferon by leukocytes. J. Immunol. Methods 48, 213-219.

Krakauer, T., 1999. Immune response to staphylococcal superantigens. Immunol. Res. 20, 163-173.

Langezaal, I., Coecke, S., Hartung, T., 2001. Whole blood cytokine response as a measure of immunotoxicity. Toxicol. In Vitro 15, $313-318$.

Langezaal, I., Hoffmann, S., Hartung, T., Coecke, S., 2002. Evaluation and prevalidation of an immunotoxicity test based on human whole blood cytokine release. Altern. Lab. Anim. (in press).

Lauw, F.N., ten Hove, T., Dekkers, P.E., de Jonge, E., van Deventer, S.J., van Der Poll, T., 2000. Reduced Th1, but not Th2, cytokine production by lymphocytes after in vivo exposure of healthy subjects to endotoxin. Infect. Immun. 68, 1014-1018.

Lehner, M.D., Morath, S., Michelsen, K.S., Schumann, R.R., Hartung, T., 2001. Induction of cross-tolerance by LPS and highly purified lipoteichoic acid via different Toll like receptors independent of paracrine mediators. J. Immunol. 165, 5161-5167.

Llewelyn, M., Cohen, J., 2002. Superantigens: microbial agents that corrupt immunity. Lancet Infect. Dis. 2, 156-162.

Michie, C.A., Cohen, J., 1998. The clinical significance of T-cell superantigens. Trends Microbiol. 6, 61-65.

Morath, S., Geyer, A., Hartung, T., 2001. Structure-function relationship of cytokine induction by lipoteichoic acid from Staphylococcus aureus. J. Exp. Med. 193, 393-397.

Reinke, P., Docke, W.D., Kox, W., Zuckermann, H., Volk, H.D., 1999. New developments in the immunodiagnosis of patients in intensive care. Dtsch. Med. Wochenschr. 124, 1527-1529.

Swaak, A.J., van den Brink, H.G., Aarden, L.A., 1997. Cytokine production in whole blood cell cultures of patients with rheumatoid arthritis. Ann. Rheum. Dis. 56, 693-695.

Szopinski, J., von Kleist, S., Panorska, A., Roginska, E., Rogala, E., Rowinska-Zakrzewska, E., 1999. Secretion of interleukin-2 (IL2) and interferon (IFN gamma) in whole blood cell culture stimulated with mitogens in patients with lung neoplasms. Pneumonol. Alergol. Pol. 67, 504-510.

van Crevel, R., van der Ven-Jongekrijg, J., Netea, M.G., de Lange, W., Kullberg, B.J., van der Meer, J.W., 1999. Disease-specific ex vivo stimulation of whole blood for cytokine production: applications in the study of tuberculosis. J. Immunol. Methods 222, $145-153$.

Vingerhoets, J., Dohlsten, M., Penne, G., Colebunders, R., Sansom, D., Bosmans, E., Kestens, L., Vanham, G., 1998. Superantigen activation of CD4+ and CD8 + T cells from HIV-infected subjects: role of costimulatory molecules and antigen-presenting cells (APC). Clin. Exp. Immunol. 111, 12-19.

Volk, H.D., Thieme, M., Heym, S., Docke, W.D., Ruppe, U., Tausch, W., Manger, D., Zuckermann, S., Golosubow, A., Nieter, B., et al., 1991. Alterations in function and phenotype of monocytes from patients with septic disease-predictive value and new therapeutic strategies. Behring Inst., 208-215.

von Aulock, S., Boneberg, E.M., Hartung, T., 2000. Intermittent G- 
CSF (filgrastim) treatment cannot induce lymphocytosis in volunteers. Clin. Pharmacol. Ther. 68, 104.

Westerholt, S., Hartung, T., Tollens, M., Gustrau, A., Oberhoffer, M., Karch, H., Klare, B., Pfeffer, K., Emmrich, P., Oberhoffer, R., 2000. Inflammatory and immunological parameters in children with haemolytic uremic syndrome (HUS) and gastroenteritispathophysiological and diagnostic clues. Cytokine 12, 822-827.

Wilson, B.M., Severn, A., Rapson, N.T., Chana, J., Hopkins, P., 1991. A convenient human whole blood culture system for study- ing the regulation of tumour necrosis factor release by bacterial lipopolysaccharide. J. Immunol. Methods 139, 233-240.

Zangerle, P.F., De Groote, D., Lopez, M., Meuleman, R.J., Vrindts, Y., Fauchet, F., Dehart, I., Jadoul, M., Radoux, D., Franchimont, P., 1992. Direct stimulation of cytokines (ㄴ-1 beta, TNF-alpha, IL-6, IL-2, IFN-gamma and GM-CSF) in whole blood: II. Application to rheumatoid arthritis and osteoarthritis. Cytokine 4, $568-575$. 